\title{
AÇÃO POLÍTICA E AFIRMATIVA: DANÇA E CORPO NO DISCURSO EDUCACIONAL SUL-AFRICANO PÓS-APARTHEID ${ }^{1}$
}

\author{
Profa. Dra. Ida Mara Freire ${ }^{2}$ \\ PPGE - UFSC \\ idamara@ced.ufsc.br
}

\section{Introdução}

Em concordância com Ann Cooper Albrigth (2003) assinalo que os discursos sobre a diferença têm ajudado os estudiosos e professores da área de conhecimento da dança a reavaliar as experiências e as tradições apresentadas pelas tendências dominantes da história da dança. O impacto da desconstrução dos cânones históricos e das suposições estéticas repercutido no ensino da dança, na leitura de Albright (2003), tem gerado certo mal-estar entre professores e dançarinos. Neste sentido, parece relevante atentar para o discurso acerca do espaço pedagógico como um lugar de acolhimento das diferenças culturais.

Nos seus estudos acerca do ensino da dança em populações politicamente marginalizadas, tais como Oriente Médio, África e Ásia, Nicholas Rowe (2008) investiga se é possível ensinar dança sem ensinar o que dançar. Sua proposição de um movimento cultural anti-hegemônico desafia o imperialismo cultural e a construção de uma polaridade cultural. Deste modo, uma ação anti-hegemônica sustenta um objetivo de criar uma autonomia que é cultural, ambiental e inerentemente dinâmica e auto-referente. Tal ação é direcionada pelas necessidades da comunidade local, com referências de seu passado, suas experiências e crenças presentes e, suas expectativas futuras, contrapondo atender as necessidades e expectativas culturais de fora da comunidade.

Penso que essas questões guardam estritas relações com as políticas públicas, a diversidade e a educação, quando examinadas à luz das experiências sul-africanas aqui apresentadas. Afinal, o mundo testemunha atentamente os desdobramentos da recente transição do regime apartheid para governo democrático sul-africano. A África do Sul apresenta-se hoje como um modelo de unidade 
na diversidade, e por várias vezes tem sido mencionada como uma "nação arco-íris". Notavelmente, nesta transição os diferentes grupos e seus membros redesenham e se afirmam tendo em vistas um retorno aos valores familiares e religiosos (MURITHI, 2009). Numa segunda visita à esse país, tenho estudado sobre a contribuição da dança no processo de reconciliação. Assim, pautado nas minhas primeiras leituras acerca do ensino da dança neste contexto, tenho como objetivo ao escrever esse texto: apresentar brevemente a dança no contexto educacional sul-africano. Especificamente, teço comentários sobre a dança como ação política; e, exemplifico a noção de corpo como afirmação da alteridade. Escrevo uma notação vinculando corpo, dança e perdão. Concluo o texto ao mencionar a dança e a reconciliação e, com isto, anuncio novos começos na educação.

\section{Dança e Educação no Contexto Sul-Africano}

Nas escolas da África do Sul a dança foi instituída por políticas propostas pelo governo apartheid (1948-1993). O estudo de Jill Waterman e Jennifer van Papendorp (1997) informa que neste período as escolas e o apoio financeiro para dança educação eram separados de acordo com as raças: branca (White), pessoa de cor (Coloured), incluía indianos e mestiços; e, nativos (Indian), neste caso, negros. O governo Nacionalista, dirigido por um estilo patriarcal de educação cristã, não considerava a dança educação uma prioridade no campo da educação formal. Nesta perspectiva, o balé clássico apresentava-se como uma forma superior de arte, se tornando um estilo dominante de dança a ser ensinada num número limitado de escolas. Poucos professores ou coreógrafos de balé clássico iriam desafiar a censura e os princípios cristãos, arriscando apresentar em palco conteúdo sexual ou questões políticas. Desta maneira, a ideia da dança apoiar valores culturais de uma elite, servindo primariamente a classe média branca sul-africana, foi transferida facilmente como um conceito para o governo apartheid. Por outro lado, as outras formas de artes originadas pelos nativos sul-africanos eram apresentadas como sendo de menos valor. Essa hierarquia de valores culturais era refletida no sistema escolar.

A dança era ensinada com um viés racista, cada raça aprendia a dança de seu grupo racial. No que se refere às questões de gênero, o atrelamento da dança no departamento da educação física 
favorecia que alguns professores separassem as meninas para fazerem dança e os meninos eram enviados para fazerem "outras coisas". As autoras indagam: o que estava sendo dito para os meninos e o que estava sendo dito para a sociedade sobre gênero e dança?

Muitas mudanças foram feitas no governo após 1994 para que a política na educação nacional mudasse seu foco, tornando-se acessível, promovendo a equidade e sendo de qualidade. Por fim, oferecendo o direito a todos os sul-africanos de valorização e de experiência de sua própria herança cultural, e a possibilidade de compartilhar isso com outros. No ensino de artes a mudança acontece gradualmente, de uma orientação disciplinar ocidental para uma abordagem de arte africana, inclusiva e integrada; combinando prosa, poesia, narração de estórias, música, canções, dança, figurinos e artefatos. Deste modo, na África do Sul pós-apartheid foi decidido adotar uma educação baseada em resultados, porém transformativa. Um sistema de educação e formação humana que integra o mental e o manual, o acadêmico e o vocacional; estes são apresentados conjuntamente em áreas de aprendizagem com intuito de produzir programas transdisciplinares. $\mathrm{Na}$ dança, busca-se formar dançarinos pensantes pautando num desenvolvimento cultural flexível, superando o estigma atrelado à dança como uma atividade meramente física.

Mediante essas mudanças, os resultados esperados dos estudantes são bem diferentes de outros países. Por exemplo: O estudantes devem ser capaz de: 1. aplicar o conhecimento, a técnica e a habilidade para criar e ser envolvido criticamente no processo e no produto artístico e/ou cultural; 2. usar o processo criativo de arte e cultura para desenvolver e aplicar as habilidades interativas e sociais; 3. refletir e engajar-se criticamente com o trabalho e experiência artística; 4. demonstrar um conhecimento da origem, função e natureza da dinâmica cultural; 5. experienciar e analisar o papel da mídia na cultura popular e seus impactos nas formas múltiplas de comunicação e expressão das artes; 6. usar as habilidades de expressão cultural para fazer uma contribuição econômica para si e para a sociedade; 7. demonstrar habilidade para acessar a arte criativa e o processo cultural para desenvolver auto-estima e promover cura; 8. conhecer, compreender e promover historicamente as formas, as práticas de arte e cultura marginalizadas (SOUTH AFRICA, 2002).

Os métodos de ensino também se modificaram, abandonam-se as metodologias centradas no modelo patriarcal, de professor autoritário ministrando disciplinas específicas e no seu lugar 
propõe-se uma metodologia mais participativa, democrática, integrada e centrada no aluno. Neste contexto, as estratégias de ensino são baseadas no entendimento que aprendizagem acontece quando o estudante participa, se diverte, se comunica, sente-se bem sobre si mesmo e não está atemorizado. No que diz respeito às estratégias de avaliação, essas são também diferentes: elas focam no que o estudante pode fazer e não no que ele não pode, enfatiza-se o sucesso e não o fracasso. Jill Waterman e Jennifer van Papendorp (1997) identificam que essa mudança cultural e o ambiente educacional são territórios muitos disputados, deles emergem atitudes favoráveis às mudanças e outras que resistem às mudanças criando paradoxos na dança no contexto educacional.

Neste cenário, por exemplo, há ainda a cuidadosa incumbência de preparar os futuros professores de dança para uma realidade cujas dificuldades encontradas no dia-a-dia nas escolas de ensino médio desafiam o idealismo de qualquer docente. Sharon Freedman (2008) inclui também a batalha diária dos alunos dispostos e interessados na aprendizagem, o aumento da violência, tanto entre alunos quanto entre alunos e professores. Esta situação é agravada pela falta de tempo suficiente para fornecer, no prazo de um calendário generalista, uma aula prática com duração adequada para acomodar os conteúdos teóricos e práticos dos manuais de dança. A tarefa de todos os intervenientes na formação de professores, portanto, não é apenas preparar os professores para serem capazes de lidar com tais problemas, mas também, forjar neles um compromisso com a reflexão crítica e modos criativos de responder aos desafios acima.

A coreógrafa sul-africana Juanita Finestone-Praeg (2011), atenta às lições do educador Paulo Freire, acredita que não se deveria aprender apenas por modos racionais, cognitivos. Ela tem como convicção que o ser inteiro do estudante precisa ser empenhado e estimulado na experiência de aprendizagem para retomar e participar do diálogo de revolta artística e política. O ato de aprender é exatamente um ato ou desempenho que requer a presença ativa do estudante participante no processo e na experiência de aquisição do conhecimento. Sua metodologia pedagógica está baseada nas tentativas de envolver o professor e o estudante de tal modo que ambos incorporem, experienciem e processem o assunto estudado e o contexto da aprendizagem.

\section{Dança como Ação Política}


Os arquitetos do apartheid concebiam as culturas como entidades definidas, fixas e homogêneas. Mas, cultura não é somente a conotação de símbolos, valores e crenças de um povo, mas as várias maneiras que esse povo responde às circunstâncias. O que os Sul-Africanos chamam de "teatro de protesto" (protest theater) é sem dúvida alguma uma ação política. A dança pode agir como catalisadora da ação e do pensamento político. A dança pode ser também, política no que se refere aos valores estéticos vinculados ao ato de dançar. As atitudes e ações políticas influenciam as formas de dançar e os caminhos pelo qual a dança é transformada. Sylvia Glasser (1991) argumenta que dançar é político, e isso não quer dizer que a dança é só política. Pois, o aspecto político é apenas uma faceta da multiplicidade de elementos que contribuem para a criação e expressão da dança. Dança e música tem sido central na expressão de frustração e raiva, bem como, na aspiração de um novo tempo.

Afinal, “todas as mágoas são suportáveis quando fazemos delas uma história ou contamos uma história a seu respeito" considera Isak Dinesen apud Arendt (1995). E isso vem ao encontro da proposição da dança como ação que ao mesmo tempo em que sugere um retorno às coisas mesmas, promove um novo começo. Destarte, a noção de natalidade em Hannah Arendt pode ser compreendida na sua Teoria da Ação, onde ela vinculará o nascimento de novos seres humanos e o novo começo com a faculdade de agir. Assim, ela descreve a natureza do início como que se comece algo novo,

[...] algo que não pode ser previsto a partir de coisa alguma que tenha ocorrido antes. Este cunho de surpreendente imprevisibilidade é inerente a todo início e a toda origem. Assim, a origem da vida a partir da matéria inorgânica é o resultado infinitamente improvável de processos inorgânicos, como é o surgimento da Terra do ponto de vista dos processos do universo, ou a evolução da vida humana a partir da vida animal. O novo sempre acontece à revelia da esmagadora força das leis estatísticas e de sua probabilidade que, para fins práticos e cotidianos, equivale certeza; assim, o novo sempre surge sob o disfarce do milagre. $\mathrm{O}$ fato de que o homem é capaz de agir significa que se pode esperar dele o inesperado, que ele é capaz de realizar o infinitamente improvável. E isto, por sua vez, só é possível porque cada homem é singular, de sorte que, a cada nascimento, vem ao mundo algo singularmente novo. Desse alguém que é singular pode-se dizer, com certeza, que antes dele não havia ninguém. Se a ação, como início, corresponde ao fato do nascimento, se é a efetivação da condição humana da natalidade, o discurso corresponde ao fato da distinção e é a efetivação da condição humana da pluralidade, isto é do viver como ser distinto e singular entre iguais. (ARENDT, 1995, p. 191)

Uma questão surge: como a dança, uma arte não-verbal pode ser uma ação política? O motivo é que o movimento, precisamente, ao contrário da palavra, pode ser usado como veículo de comunicação que permite que a dança seja um poderoso veículo de expressão, principalmente para 
um povo oprimido. Mas, dança e dançar não são somente expressão de sentimentos políticos, ambos são influenciados pela percepção de seus participantes e observadores, contribuindo para a transformação de sistemas políticos. Na África do Sul, onde você dança, com quem você dança, e que tipo de dança você executa e sua atitude frente à dança dirá alguma coisa sobre você, como uma pessoa política, bem como sobre você, como pessoa artista (GLASSER, 1991). Nesta cena, evidencia o corpo que dança e afirma a alteridade.

\section{Corpo como Afirmação da Alteridade}

A transformação pessoal é um pré-requisito para a transformação social na perspectiva curricular sul-africana. Através de Estudos de Dança, os estudantes desenvolvem a auto-estima, um sentimento de identidade, a confiança e auto-disciplina. Eles desenvolvem a responsabilidade social, desenvolvendo um respeito pelos seus próprios e outros corpos e explorando-os numa aprendizagem individual e colaborativa. Esses desenvolvem uma sensibilidade cultural, explorando e realizando danças de outras culturas além da sua própria. Dessa forma, eles afirmam a sua identidade cultural própria e a dos outros também (SOUTH ÁFRICA, 2008).

A dança como uma ação de comunicação corporal não está dispensada da ética. Nós sempre dançamos com o outro ou para o outro, nós nunca dançamos sozinhos. Reafirmo que a dança não é uma atividades solitária, mas um movimento solidário. Vale salientar que dançar é a tentativa de ser um com outro. O espaço da dança como estrutura coletiva sustenta as noções de acolhimento e hospitalidade.

Um exemplo que evidencia como a dança está implicada no acolhimento da diferença pode ser encontrado no trabalho do pesquisador sul-africano Gerard Samuel (2008) que examina o corpo diferente na perspectiva da "disability dance" no contexto da África urbana e contemporânea e problematiza acerca do lugar que ocupam os dançarinos com necessidades especiais e das comunidades rurais. $\mathrm{O}$ autor observa que as artes cênicas contemporâneas estão inseridas nas cidades, mas muitas comunidades do campo enfrentam isolamento e lidam com o estigma da ignorância. No entanto, o avanço tecnológico tem rompido com o abismo entre rural e urbano propiciando, por exemplo, a ocorrência de performances em locais não convencionais, subvertendo 
e celebrando outras formas de expressão. Samuel avalia que levar esse tipo de trabalho para o espaço público propicia uma interação educativa entre o artista e a pessoa que o assiste na rua, de modo que a dança cênica contemporânea começa a ficar mais exposta. Samuel exemplifica também a confrontação que o dançarino na cadeira de rodas apresenta ao dançar no espaço teatral formal, deixando um sentimento inconfortável acerca do corpo e da estética, e no contexto sul-africano há ainda a dificuldade de desvelar o corpo negro que dança - apresentado muitas vezes como exótico e nobre selvagem. O pesquisador alerta que estas dificuldades ocorrem dentro do espaço progressivo e mundialmente reconhecido da nova constituição da África do Sul. Na tentativa de questionar uma noção de estética fixa para dança cênica contemporânea ele nos desafia a aprofundar nosso entendimento acerca do corpo que dança e propõe vincular o conhecido movimento de consciência negra que defende a posição de que "Black is beautiful" e apresentar a "disability dance" como bela também.

\section{Notação sobre o Corpo, a Dança e o Perdão}

A leitura do texto de Jacques Derrida (2005) intitulado: “O perdão, a verdade e a reconciliação: qual gênero?" traz a cena vários escritos e vozes, entre eles estão a constituição da África do Sul, a autobiografia de Nelson Mandela, a voz em off de Hegel, o livro da jornalista e poeta Antjie Krog, a entrevista de Desmond Tutu à Timothy Garton, e os vívidos testemunhos das vítimas apresentados durante a - TRC Truth Reconciliation Comission (Comissão Verdade e Reconciliação). Esses discursos incrustados um no outro fazem-me pensar no perdão como uma ação e o corpo como afirmação da alteridade. Ao examinar o discurso hegeliano sobre o perdão Derrida chama a atenção para a expressão das Wort der Versöhnung: explicita que não se trata da palavra [le mot] "reconciliação", mas sim da palavra que descreve o gesto pelo qual se oferece ou se propõe a reconciliação: o estender a mão.

É fato que toda e qualquer discussão ético política sempre se dá na ambiência de um suposto "nós" unificador, dentre outros, é preciso abrir um espaço para interrogar "nós quem", argumenta Paulo Cesar Duque-Estrada (2008) ao destacar dois aspectos nos argumentos de Derrida (2005) que quer pensar essa experiência de um outro modo, para além do paradigma do todo e da reconciliação, donde o comentarista percebe traços essenciais da afirmação e do perdão. Afirmação é apresentada 
como afirmação da diferença, da heterogeneidade, e, portanto da alteridade, que para Derrida é condição inseparável de toda unidade, de toda identidade, de toda experiência de si mesmo ou de um "nós". Isso nos possibilita também ampliar a nossa visão sobre o direito e o respeito à diferença e acolhermos a singularidade humana e irmos além do discurso do conflito com a diferença. E, na perspectiva de Roland Barthes (1988), criar através do ensino da dança uma relação com a diferença que se "originaliza" pouco a pouco, pois, demanda tempo reencontrar a originalidade dos corpos tomados um a um, quebrar a reprodução dos papéis, a repetição dos discursos, evitar as encenações de prestígio e rivalidade.

Assim, uma questão se evidencia: Como a noção de perdão se aproxima ao ato de dançar? Vou tentar responder essa questão considerando que diante do desejo de se comunicar com outro, dançamos. Quando o filósofo argelino indaga sobre qual o gênero da verdade, sua resposta, primeiro, solidariza o perdão à mulher e, segundo, na revelação da verdade encena o corpo: “Não é apenas porque tantas vezes, as testemunhas sobreviventes são mulheres. Mas porque a cena do testemunho e da verdade, da revelação da verdade, encena o corpo da testemunha, que também pode ser uma vítima de tortura ou estupro" (Derrida, 2005. p. 80). Percebo no corpo uma comunicação, quando esse explicita a linguagem das marcas, das cicatrizes, quando visíveis - traços na superfície do corpo, quando invisíveis - tramas nas profundezas da alma. O corpo com sua voz silenciosa, diz tudo sem palavra alguma. O desejo do homem é o desejo de comunicação com o outro, enuncia J.D. Nasio (2009). Esse autor salienta quer se trate de uma criança de cinco anos, de uma pessoa adulta ou de nós mesmos, falamos todos a linguagem das sensações vividas anteriormente em nosso corpo de criança, ainda que não tenhamos nunca a consciência disso. A imagem inconsciente do corpo é um código íntimo, peculiar a cada um, que devemos aprender a falar, caso queiramos, estabelecer uma comunicação verdadeira uns com os outros.

O estudo da experiência da dança no discurso educacional sul-africano, como preliminarmente apresentado aqui, pode contribuir para o alargamento de nossas atitudes frente às diferenças culturais, mas para isso faz-se necessário o entrelaçar dos corpos num exame crítico sobre o ato de dançar. Pois, ensinar a dançar está vinculado em habitar o próprio corpo, mas com abertura para acolher os corpos culturalmente diferentes dos nossos. Deste modo, a experiência com a dança possibilita apresentar o corpo como base para uma comunicação responsável. Ao dançar a minha, a nossa responsabilidade para com outrem é a estrutura fundamental sobre a qual todas as 
outras estruturas sociais são acolhidas. A dança como ação política e o corpo enquanto desejo de comunicação podem sugerir uma alteridade que sustenta com responsabilidade os novos começos na educação.

\section{Dança e Reconciliação: Novos Começos em Educação}

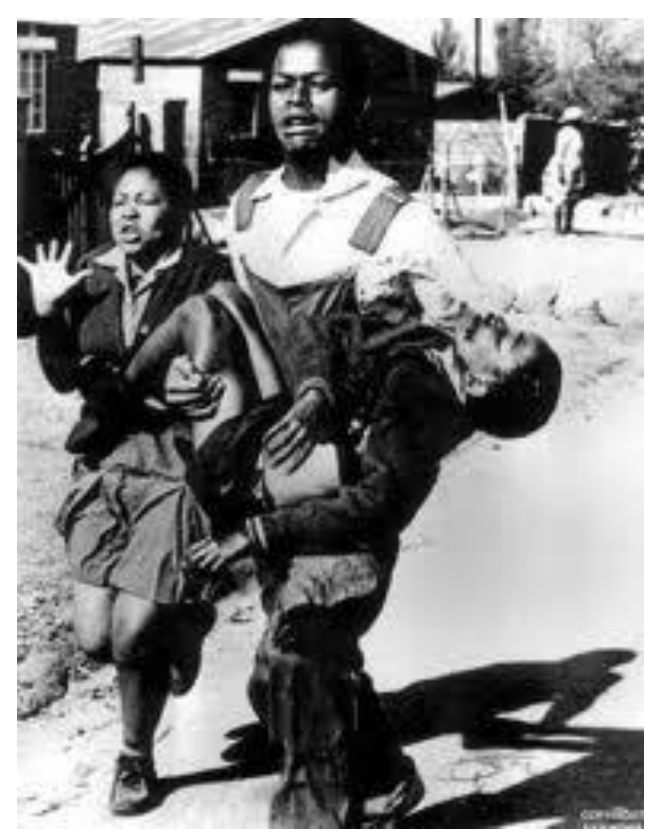

Figura 1 - Foto: Sam Nzima (Em 16 de junho de 1976, Hector Peterson carregado por Mbuyisa Makhubo, depois de ser baleado pela policia sul-africana, sua irmã Antoinette Sithole, corre ao lado deles).

Venho de tão longe pra ver de perto

Belas lições de liberdade

Gravadas à flor da pele

Escrituras sutis

Existências singelas

Alegria profunda

Pois, profunda foi a dor

Marcas - cicatrizes

Pedras - defesa - monumentos

Água - lágrimas - beleza 


\author{
Volto para casa \\ Aprendo com Hector Peterson \\ Que no caminho para escola \\ Pode-se encarar a morte \\ Porém, neste mesmo caminho \\ Pode-se encontrar a paz.
}

Estas palavras foram escritas no verso de um cartão postal, que escrevi na minha primeira visita à África do Sul em 2008. Hector Peterson (figura 1), foi uma entre as milhares de crianças vitimadas pela ação política do governo apartheid, talvez, pelo fato delas serem o futuro de uma nação. Em Soweto, a mesma rua que situa a escola, palco de manifestações estudantis, estão localizadas as residências dos dois ganhadores do prêmio Nobel da Paz: Nelson Mandela e Desmond Tutu. Volto a esse país, em 2011, para aprofundar as lições. E aprendo com Hannah Arendt que:

O milagre que salva o mundo a esfera dos negócios humanos, de sua ruína normal e "natural" é, em última análise, o fato do nascimento, no qual a faculdade de agir se radica ontologicamente. Em outras palavras, é o nascimento de novos seres humanos e o novo começo, a ação de que são capazes em virtude de terem nascido. Só o pleno exercício dessa capacidade pode conferir aos negócios humanos fé e esperança, as duas características essenciais da existência humana que a antiguidade ignorou por completo, desconsiderando a fé como virtude incomum e pouco importante, e considerando a esperança como um dos males da ilusão contidos na caixa de Pandora. Esta fé e esta esperança no mundo talvez nunca tenham sido expressas de modo tão sucinto e glorioso como nas breves palavras com as quais os Evangelhos anunciaram a "boa nova": "Nasceu uma criança entre nós. (ARENDT, 1995, p. 259)

A natalidade, enquanto essência da educação exige de nós criação para que dela tenhamos experiência. A teoria de novos começos de Hannah Arendt parece apontar ações precisas sobre o perdão, afinal, de que outro modo poderíamos compreender sua advertência de que os homens, embora devam morrer, não nascem para morrer, mas para começar? Fé e esperança: talvez, seja isso que as crianças e os jovens em geral, e os sul-africanos em particular, esperam do mundo. Um lugar onde infância e juventude não significam ameaça, mas coragem de Ser. Educar nossas crianças e jovens com dança é demonstrar que eles não estão sozinhos no mundo. Nas palavras de Arendt (1995, p. 259): 
[...] a única faculdade milagrosa que o homem possui, como Jesus de Nazaré, que vislumbrou essa faculdade com a mesma originalidade e ineditismo com que Sócrates vislumbrou as possibilidades de pensamento, deve ter sabido muito bem ao comparar o poder de perdoar com o poder mais geral de operar milagres, colocando a ambos no mesmo nível e ao alcance do homem.

Na poesia o rap sul-africano, Emile Jansen sugere que tentemos promover a paz, ao menos, e tentemos cessar a violência. Afinal, há mais vida na paz que num mundo vazio.

\footnotetext{
${ }^{1}$ Esse artigo é um dos primeiros resultados da pesquisa de estágio pós-doutoral intitulada: As vozes do silêncio: corporeidade, dança e perdão nas políticas afirmativas educacionais sul-africanas pós-apartheid, 2011. Realizado na School of Dance University of Cape Town, (Apoio: REUNI/UFSC). Agradeço a colaboração do pesquisador Gerard Samuel, bem como a interlocução com o Prof. Dr. Paulo Cesar Duque-Estrada.

${ }^{2}$ Professora Associada na Universidade Federal de Santa Catarina. Tem experiência na área de Educação. Lider do Alteritas grupo de estudos e pesquisas sobre Diferença, Arte e Educação. Diretora, coreógrafa e dançarina do Potlach Grupo de Dança. Escreve sobre os temas: alteridade, cegueira, dança e formação de professores. Autora do blog: www.escrevedance.blogspot.com/
}

\section{REFERÊNCIAS}

ALBRIGHT, Ann Cooper. Channeling the 'Other': an embodied approach to teaching across cultures. Research in dance education, v.4, n. 2, March 2003.

ARENDT, Hannah. A Condição Humana. Rio de Janeiro: Forense,1995.

BARTHES, Roland. O Rumor da Língua. São Paulo: Brasiliense, 1988.

DERRIDA, Jacques. O perdão, a verdade, a reconciliação: qual gênero? In: Evandro Nascimento. Jacques Derrida: Pensar a Desconstrução. São Paulo: Estação Liberdade, 2005. 
DUQUE-ESTRADA, Paulo Cesar. Sobretudo... o perdão - (im)possibilidade, alteridade, afirmação. In: P.C. Duque-Estrada (org.) Espectros de Derrida. Rio de Janeiro: PUC, NAU, 2008.

FINESTONE-PRAEG, Juanita. Difference is revolting. In: Proceedings of the Sixth South African Dance Conference, 2011.

FRIEDMAN, Sharon. Provisioning South African schools with effective dance educators: posing the challenges. In: Global perspectives on dance pedagogy - research and practice. Proceedings of CORD conference, 2009.

GLASSER, Sylvia. Is dance Political Movement? Journal for the Anthropological Study of Human Movement, v. 6, n.3, May, 1991.

JANSEN, EMILE. My hip hop is african \& pround. Cape Town: Cape Flats Uprising, 2005.

MURITHI, Tim. An African Perspective on Peace Education: Ubuntu Lessons in Reconciliation. International Review of Education / Internationale Zeitschrift für Erziehungswissenschaft / Revue Internationale de l'Education, v. 55, n. 2/3, May, 2009.

NASIO, J.D. Meu corpo e suas imagens. Tradução André Teles. Rio de Janeiro: Zahar, 2009.

ROWE, Nicholas. Dance education in the Occupied Palestinian Territories: Hegemony, counterhegemony and anti-hegemony. Research in dance education, v.9. n. 1, March, 2008.

SAMUEL, Gerard. Undressing the (w)rapper: Disability dance. In: Proceedings of the Fifth South African Dance Conference, 2008.

SOUTH AFRICA. National Curriculum Statement Grades 10-12 (General) Learning Programs Guidelines - Dance Studies, January 2008. Disponível em:

<http://www.education.gov.za/LinkClick.aspx?fileticket=bRus\%2BpWDDV4\%3D\&tabid=247\&mi d=595>. Acesso em 12 abr. 2011. 
SOUTH AFRICA. Revised National Curriculum Statement Grades R-9 (Schools) Arts and Culture, Pretória, 2002. Disponível em:

<http://www.education.gov.za/LinkClick.aspx?fileticket=PtLjFYqUsdY\%3d\&tabid=266\&mid=720

>. Acesso em 15 abr. 2011.

WATERMAN, Jill, PAPENDORP, Jennifer van. Dance culture, education and the south african context. In: Proceeding at the First South African Music and Dance Conference incorporatin the $15^{\text {Th }}$ Symposium on Ethnomusiculog, 1997. 